\title{
Redescoberta de Dalechampia riparia L.B. Sm \& Downs (Euphorbiaceae), Espécie Endêmica de Santa Catarina, Brasil
}

\author{
Dilana Ferreira da Silva ${ }^{1}$, Inês Cordeiro ${ }^{2}$ \& Mara Rejane Ritter ${ }^{1}$
}

Recebido em 16/04/2020 - Aceito em 05/05/2020

\footnotetext{
1 Universidade Federal do Rio Grande do Sul/UFRGS, Programa de Pós-Graduação em Botânica, Laboratório de Taxonomia/LabTax, Porto Alegre/RS, Brasil. CEP: 91.501-970. < dilana.ferreira@yahoo.com.br, mara.ritter@ufrgs.br>.

2 Instituto de Botânica de São Paulo/IBot, São Paulo/SP, Brasil. CEP: 04.301-902. <isandona@uol.com.br>.
}

RESUMO - Dalechampia riparia foi descrita por Smith \& Downs durante os estudos da família Euphorbiaceae para a flora de Santa Catarina. O único registro dessa espécie era o material-tipo coletado em 1956. Após 61 anos, a espécie que era considerada possivelmente extinta, foi coletada novamente na localidade-tipo, município de Ibirama. Apresentamos um relato sobre os indivíduos encontrados, bem como seu habitat e seu estado de conservação, aqui analisado. Além disso, disponibilizamos uma atualização da descrição da espécie, juntamente com imagens e aspectos morfológicos de táxons simpátricos, como D. clausseniana Baill., D. ficifolia Lam. e D. stipulacea Mül. Arg. Dessa forma, enfatizamos a necessidade de compreensão, obtenção de informações e coletas da nossa flora, a fim de evitar a real extinção dessas espécies.

Palavras-chave: Espécie ameaçada; sul do Brasil; trepadeira.

\section{Rediscovery of Dalechampia riparia L.B.Sm \& Downs (Euphorbiaceae), an Endemic Species in Santa Catarina, Brazil}

ABSTRACT - Dalechampia riparia was described by Smith \& Downs during the botanical study of family Euphorbiaceae for the Santa Catarina flora. The only register of this species is the type-material collected in 1956. After 61 years, this species, that had been considered possibly extinct, was collected in the same type-locality, in municipality of Ibirama. We present a report on the individuals that were found, as well as their habitat and conservation status, which were analyzed. We also provide a update taxa description, along with image and morphological aspects of sympatric species, D. clausseniana Baill., D. ficifolia Lam. and D. stipulacea Mül. Arg. In doing so, we emphasize the need to comprehend and obtain information and collections of our flora, in order to avoid the real extinction of these species.

Keywords: Endangered species; southern Brazil; climber.

\section{Redescubrimiento de Dalechampia riparia L.B.Sm \& Downs (Euphorbiaceae), una Especie Endémica en Santa Catarina, Brasil}

RESUMEN - Dalechampia riparia fue descrita por Smith \& Downs durante los estudios de la família Euphorbiaceae para la flora de Santa Catarina. El único registro de esta especie se el material-tipo recolectado en 1956. Después de 61 años, la espécie que se considero posiblemente extinto, se recolectó nuevamente en la localidade-típica, el município de Ibirama. Presentamos un informe de los individuos encontrados, así como su hábitat y su estado de conservación, analizado aqui. Además, proponemos uma actualización descripción de las taxones, junto con imágenes y aspectos morfológicos de especies simpátricas, tales como D. clausseniana Baill., D. ficifolia Lam. y D. stipulacea Mul. Arg. Por ló tanto, enfatizamos la necesidad de comprender, obtener información y colecciones de nuestra flora, para evitar la verdadera extinción de estas especies.

Palabras clave: Especies en peligro de extinción; sur de Brasil; enredadera. 


\section{Introdução}

Dalechampia foi descrito por Linnaeus na obra Genera Plantarum (1754), em homenagem ao médico e botânico francês Jacques Dalechamp (Smith \& Downs 1988), e pertence à família Euphorbiaceae, subfamília Acalyphoideae, tribo Plukenetieae e subtribo Dalechampiinae (Webster 1994). É um gênero pantropical com, aproximadamente, 120 espécies, com maior riqueza específica na região neotropical, sendo que 90 espécies são americanas e as demais estão distribuídas pela África, Madagascar, Índia, e apenas uma espécie se estende até o sul da China e Java (Stevens 2018, Radcliffe-Smith 2001). O Brasil abarca a maioria das espécies do gênero, com 72 táxons amplamente distribuídos em todos os estados e biomas (Webster \& Armbruster 1991; Flora do Brasil 2020, em construção).

Das espécies ocorrentes no Brasil, a maioria possui hábito trepador, e uma pequena proporção é subarbustiva, ereta ou procumbente (Webster 1989, Webster \& Armbruster 1991, Webster 1991). As folhas de Dalechampia apresentam uma grande variação de formas, tamanhos $e$ texturas, tornando difícil a sua identificação na fase vegetativa. Podem ser simples ou compostas, inteiras ou lobadas, lanceoladas, ovadas, oblongas ou elípticas (Webster \& Armbruster 1991, Cordeiro 1998, Pereira-Silva et al. 2016). Contudo, no período de floração e frutificação, o gênero é facilmente reconhecido devido a sua peculiar inflorescência, um pseudanto que é formado basicamente por duas subinflorescências (pistiladas e estaminadas), envoltas por duas brácteas involucrais, que as protegem (Radford et al. 1998).

Entre os estudos taxonômicos desenvolvidos com o gênero na região Sul do Brasil, podem ser citados Rambo (1960) e Allem \& Waechter (1977) para o Rio Grande do Sul; Smith \& Downs (1988) para Santa Catarina; estudos florísticos para o Paraná (Rosseto \& Vieira 2013, Garcia et al. 2017, Trochez et al. 2017, Bechara et al. 2018, Dettke et al. 2018).

No decorrer do estudo taxonômico do gênero Dalechampia no sul do Brasil, coletou-se D. riparia em sua localidade tipo. Assim, o objetivo deste trabalho é fornecer informações atualizadas quanto à espécie, bem como verificar o seu estado de conservação.

\section{Material e Métodos}

Realizou-se uma saída de campo para a localidade do material-tipo onde foi coletada a espécie, com o intuito de averiguar se ela ainda existia no local. Além das atividades de campo, buscaram-se exemplares depositados nos herbários HBR e R, bem como a imagem do holótipo disponível no Herbário Virtual Reflora (www.reflora.jbrj.gov.br). O protólogo foi analisado, bem como outros trabalhos reportados à espécie. Dos materiais coletados, apenas um apresentava fruto jovem, impossibilitando a averiguação de características mais expressivas. $\mathrm{O}$ estado de conservação da espécie foi estabelecido com base nos critérios da International Union for Conservation of Nature (IUCN) $(2012,2017)$. Os acrônimos dos herbários são citados de acordo com Thiers (2018). As ilustrações foram feitas pela artista plástica Regina Maria Alcântara de Carvalho $e$ as imagens fotográficas pela autora principal.

\section{Resultados e Discussão Tratamento taxonômico}

Dalechampia riparia L.B. Sm. \& Downs, Sellowia, 11: 153. 1959.

Tipo: Brasil, Santa Catarina, Ibirama, beira do rio, alt. 100m, 12 dezembro 1956, R. Reitz \& R.M. Klein 3834 (holótipo US, barcode US 00096465; isótipo HBR, barcode HBR 0014551). Figura 1.

Material adicional examinado: Brasil. Santa Catarina, Ibirama, BR 470, próximo ao rio Itajaí-Açú, 2705'18"S 49²8'06”W, 3 novembro 2017, (est.), D.F. Silva 39 (ICN 166892); idem, no interior da cidade 2701"57"S 49³2"06"W, 3 novembro 2017, (fl., fr.), D.F. Silva 42 (ICN 166894). Figura 2.

Descrição: Trepadeira volúvel. Ramos levemente estriados, pubescentes a hirsutos, 1-2mm diâm. Folhas simples, 3-lobadas, membranáceas: estípulas, 5-7,7 x 1,8-2mm, lanceoladas, esparsamente pilosas, pecíolo 5-8cm compr., pubescente a hirsuto, estriado; estipelas 2 , lineares a lanceoladas, 1,6-3,6mm compr., pilosas, com glândulas; lâminas foliares $3-10 \times 4-12 \mathrm{~cm}$, base cordada, lobos de ápice agudo a caudado, face adaxial esparsamente pilosa, pubescente sobre as nervuras principais, face abaxial pubescente a vilosa, margens serreadas, ciliadas; nervuras 
salientes na face abaxial; venação actinódroma. Inflorescências axilares; pedúnculo $2-6 \mathrm{~cm}$ compr., hirsuto, estriado; brácteas involucrais $2-3,5 \times 2-3,3 \mathrm{~cm}$, verde-amareladas, ovadas, pubescentes, margem serreada, ciliada com tricomas glandulares, 3-lobadas, base arredondada a subcordada, ápice agudo, acuminado, nervuras principais 6-9; estípulas do invólucro $6-8 \times 1,5-2 \mathrm{~mm}$, lanceoladas, pilosas, base truncada, ápice arredondado, margem inteira, ciliada, com tricomas glandulares na base e no ápice. Subinflorescência estaminada: bractéola involucral 1, pubérula, reniforme, margem não-ciliada, pedunculada; bractéolas resiníferas laminares ca. 4mm compr., resina amarelo-clara. Flores estaminadas 8, sépalas 4-5, pubérulas, lanceoladas, 35 estames. Subinflorescência pistilada: bractéola externa 1 , reniforme a ovada, $4 \times 3-5 \mathrm{~mm}$, pilosa, margem inteira, ciliada, com tricomas glandulares; bractéola interna 1, expandida, margem inteira, ciliada, com tricomas glandulares. Flores pistiladas pediceladas, 8-10 sépalas, pinatissectas, tricomas tectores simples, pinas com uma glândula na porção distal; ovário globoso, pubescente; coluna estilar $6-8 \mathrm{~mm}$ compr., ápice capitado. Fruto: cápsula trígona. Semente: não vista.

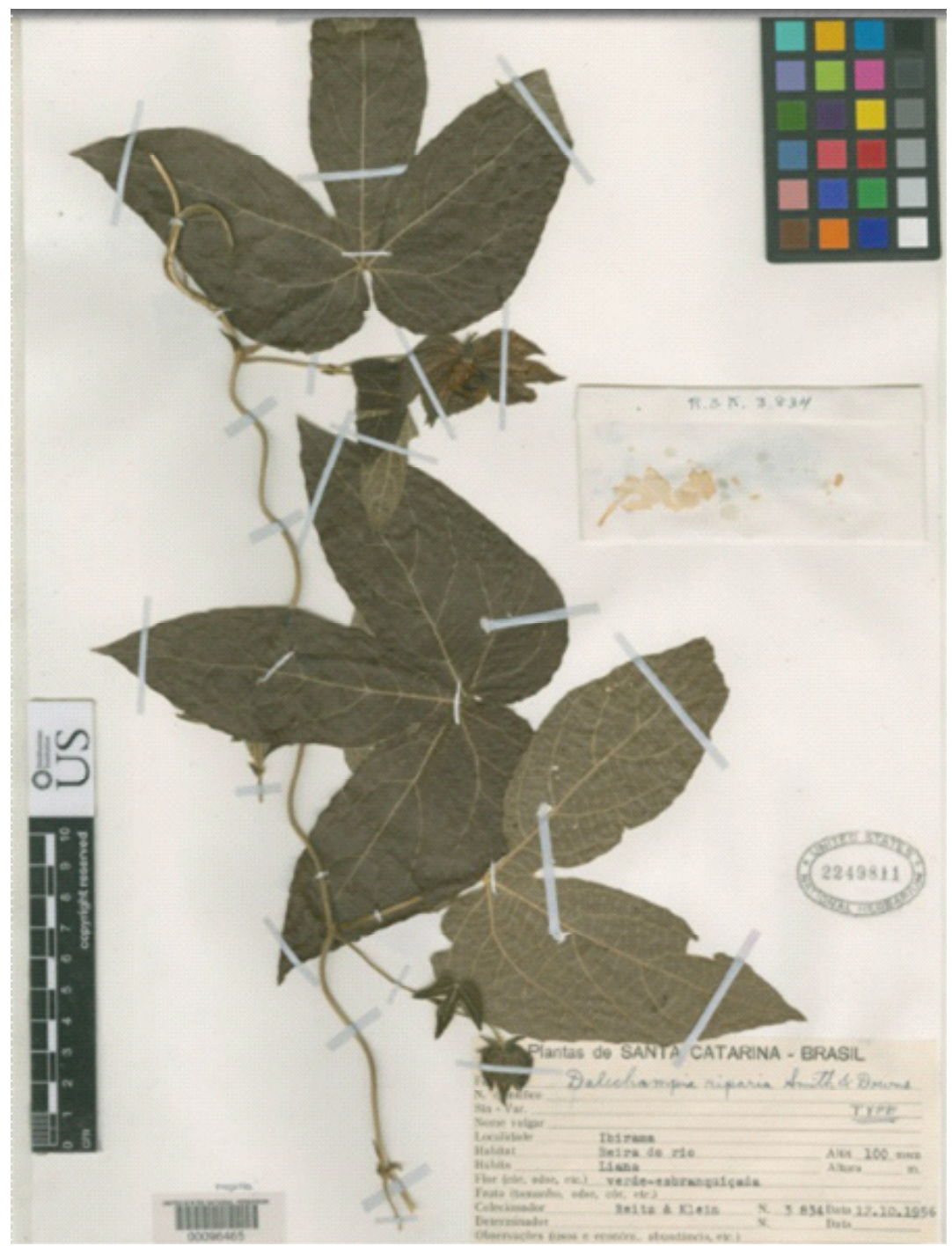

Figura 1 - Holótipo de Dalechampia riparia L.B. Sm. \& Downs. Fonte: Herbarium US, Smithsonian Institution. 
Distribuição: espécie endêmica do município de Ibirama (Figura 2), Santa Catarina, Brasil (Smith \& Downs 1988, Vibrans et al. 2014).

Habitat: Dalechampia riparia foi encontrada em beira de estrada ou borda da mata, geralmente próxima a algum rio. Cresce sobre árvores ou arbustos, sendo observada com até 5 metros de altura.

Status de Conservação: Dalechampia riparia foi considerada uma espécie provavelmente extinta na natureza, com esforços esgotados na sua busca (Vibrans et al. 2014, Brasil 2014). Porém, com as novas informações aqui apresentadas, podemos reavaliar a categoria anteriormente proposta. Trata-se de uma espécie rara, que ocorre exclusivamente no município de Ibirama, ocupando uma área de cerca de $20 \mathrm{~km}^{2}$. Segundo os critérios da IUCN (2017), a espécie deve ser considerada Criticamente em Perigo (CR B2ab [iii, iv]).

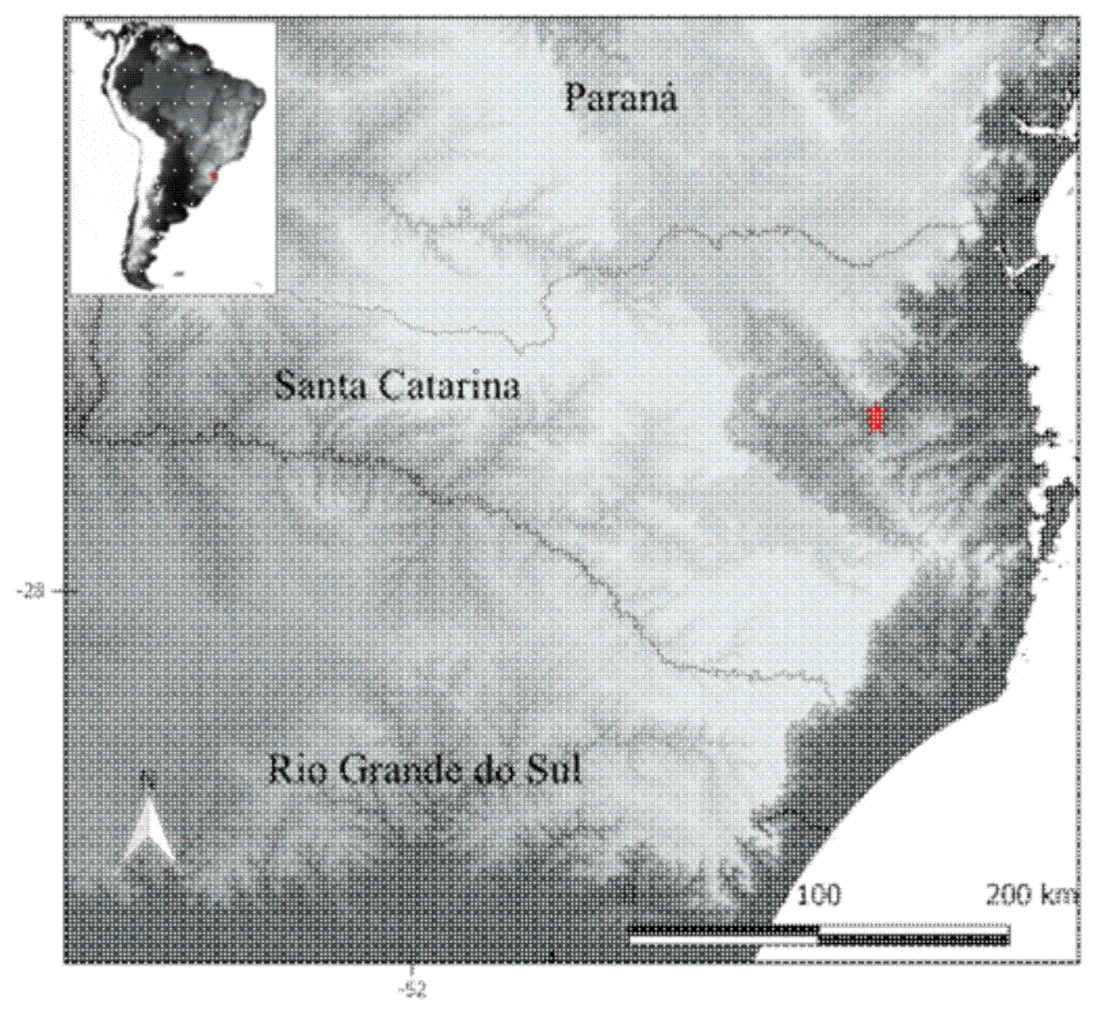

Figura 2 - Mapa de distribuição de Dalechampia riparia. Fonte: Dados coletados a campo e passados para o QGIS 2.18.

Apenas dois indivíduos foram encontrados em pontos diferentes da cidade, com uma área de ocupação densa, por se tratar de trepadeiras. Entretanto, Armbruster (1982) averiguou em algumas espécies de Dalechampia que suas sementes e plântulas são suscetíveis a predadores e patógenos, como no caso da larva do lepidóptero Dynanime mylitta $\mathrm{Cr}$., o qual ocasiona alto índice de predação dos frutos, quando ainda jovens. $\mathrm{E}$ este, aliados a fatores naturais como competição por luz, nutrientes e água, acabam restringindo o desenvolvimento de novos indivíduos. Em outras espécies de Dalechampia foi encontrada dormência mecânica da semente (Sanches 1997), sendo este também um fator limitante para a dispersão das espécies.

Quando descrita, a espécie foi caracterizada como endêmica e restrita de Ibirama, Santa Catarina (Smith \& Downs 1959) e, de fato, só foi encontrada novamente na mesma localidade. Quanto às demais exsicatas depositadas em herbários e identificadas anteriormente como Dalechampia riparia, coletadas em Londrina/ PR (RB00593847, MBM265912, PACA37316), constatou-se que se tratava de D. reitzkleinii L.M. Sm \& Downs. 
Há outras espécies de Dalechampia que ocorrem simpatricamente com D. riparia (Figura 3). São elas: D. clausseniana Baill., D. ficifolia Lam. e D. stipulacea Müll. Arg. (Flora do Brasil 2020, em construção). Dentre estas, a mais distinta de D. riparia é D. clausseniana (Figura 4A) por apresentar folhas compostas trifolioladas. As demais apresentam folhas simples trilobadas e chegam a alcançar o dossel das árvores. Dalechampia ficifolia (Figura 4B, Figura 4E) se diferencia pelo indumento ferrugíneo nos ramos e na face abaxial das folhas, estípulas oblongas a arredondadas $e$ brácteas involucrais alvas. A única espécie que realmente pode ser confundida com $D$. riparia é D. stipulacea, pois o aspecto foliar e a fisionomia de ambas são extremamente semelhantes. Entretanto, as estípulas foliares de $D$. stipulacea são ovadas e, geralmente, com tricomas glandulares nas margens e apresentam parastípulas laciniadas com tricomas glandulares (Figura 4C, Figura 4F, Figura 4G).

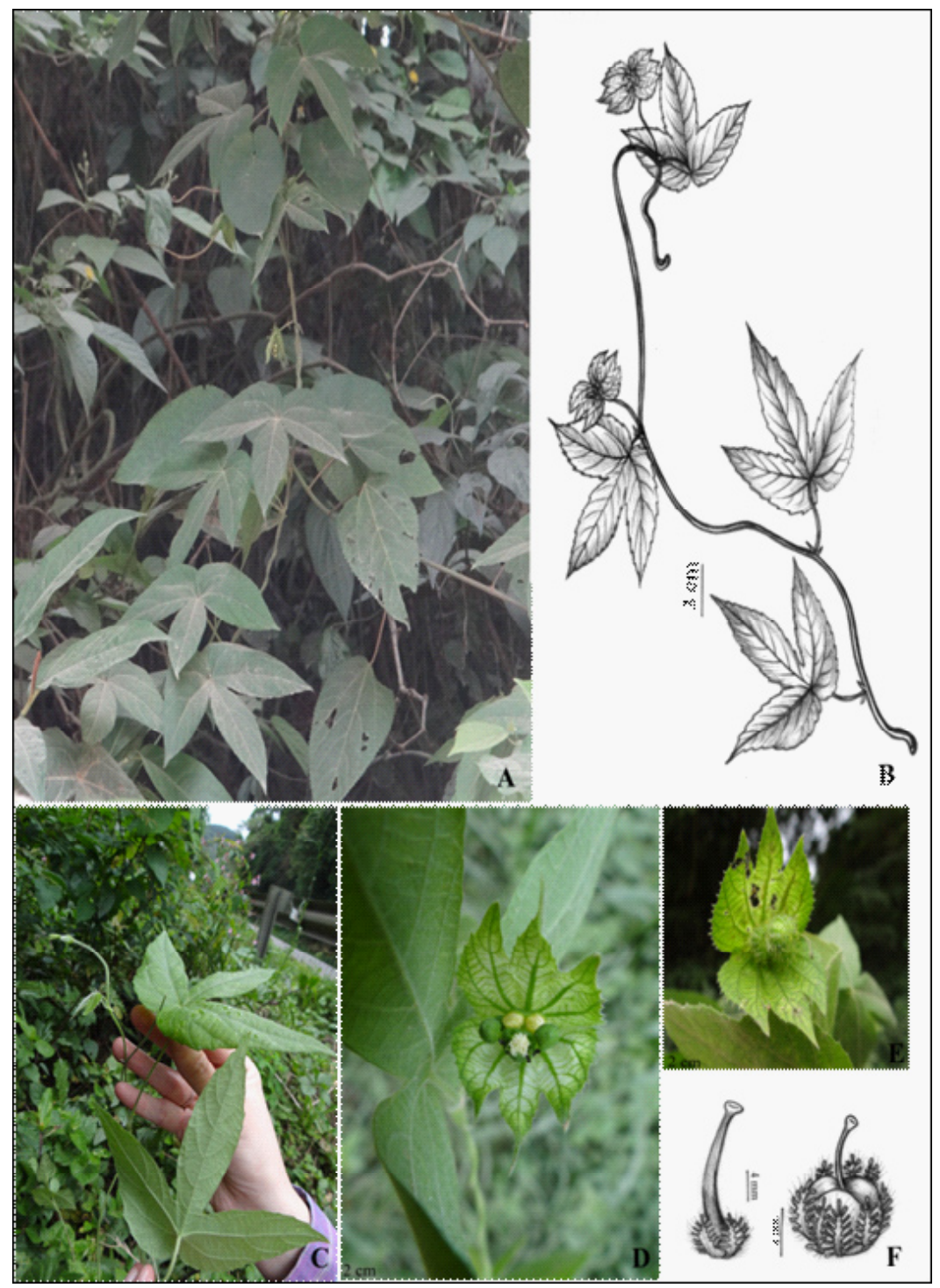

Figura 3 - Dalechampia riparia; A: Hábito; B: Ramo com inflorescência; C: Detalhe das folhas, face adaxial e abaxial; D: Pseudanto; E: Pseudanto com fruto jovem; F: Flor pistilada com cálice de sépalas pinatissectas (esquerda) e fruto jovem (direita). 


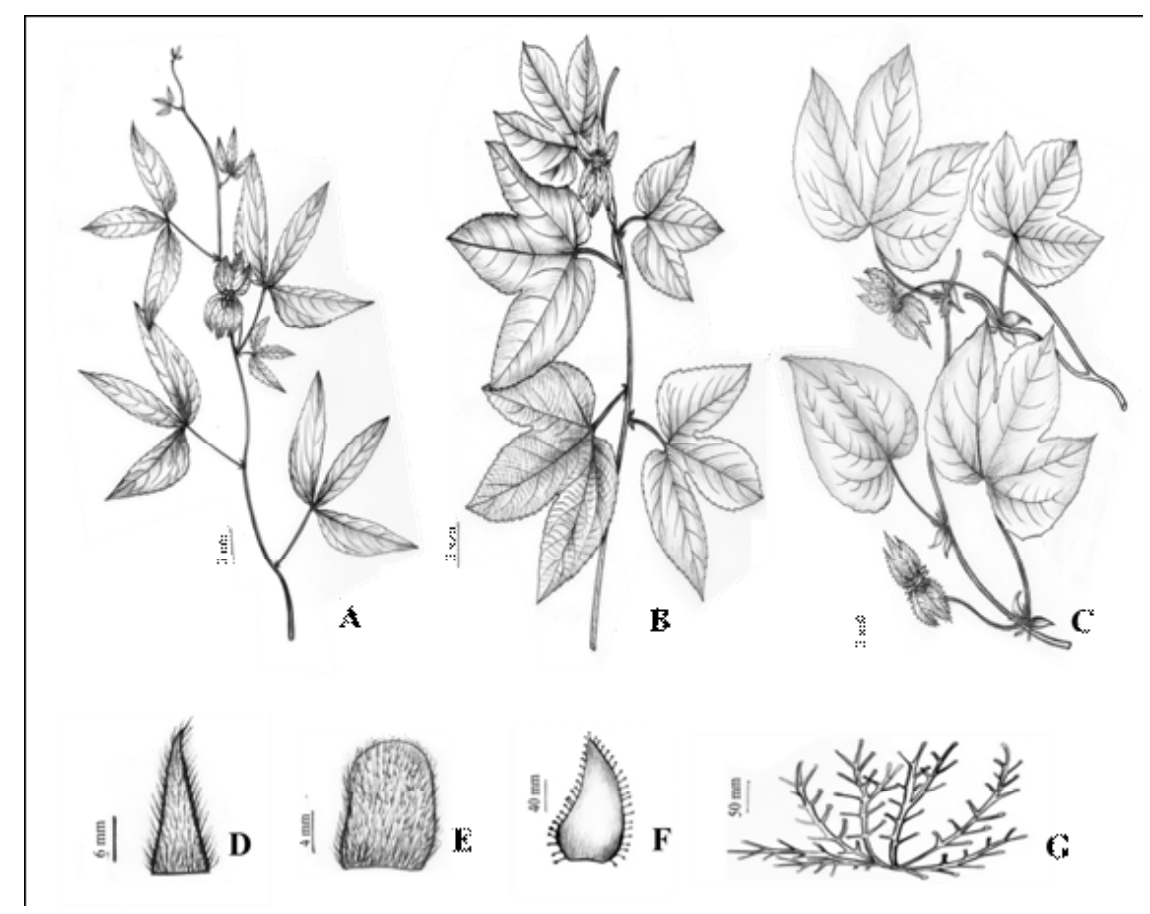

Figura 4 - A: Hábito de Dalechampia clausseniana; B e E: Hábito e estípula foliar de Dalechampia ficifolia; C, F e G: Hábito, estípula foliar e parastípula de Dalechampia stipulacea; D: Estípula foliar de Dalechampia riparia.

\section{Conclusão}

O estado de Santa Catarina possui uma riqueza inestimável, com espécies de diferentes grupos vegetais ainda sendo descritas (Dalmolin etal.2015, Hasseme \& Rønsted 2016, Sobral etal. 2019, Vieira 2020) ou redescobertas (Funez et al. 2016, 2017). Parte dessa riqueza está registrada em publicações, de 1951 a 2005, do projeto Flora Ilustrada Catarinense, que foi um marco para o conhecimento botânico no estado. Mais recentemente, o Inventário Florístico Florestal de Santa Catarina (IFFSC) atualizou muitos dados botânicos e de conservação de espécies. Apesar desses projetos, ainda há muitos grupos não estudados e que necessitam de um maior esforço de coletas nos mais diversos ambientes do estado de Santa Catarina. A preocupação com o status de conservação dessas espécies também precisa ser cuidadosamente averiguada e anunciada à sociedade, para que esta possa reconhecer e preservar a nossa flora.

\section{Agradecimentos}

Nós gostaríamos de agradecer à Coordenação de Aperfeiçoamento de Pessoal de Nível Superior (CAPES), pela bolsa concedida à primeira autora. Agradecemos também ao colega biólogo Élinton L. Rezende, pela disponibilidade, persistência e auxílio no trabalho de campo, e à artista plástica Regina Maria Alcântara de Carvalho, pelas ilustrações.

\section{Referências}

Allem AC \& Waechter JL. Notas sistemáticas y nuevos sinónimos en Euphorbiaceae de America del Sur - II. Revista Brasileira de Biologia, 37: 91-101, 1977.

Armbruster WS. Seed production and dispersal in Dalechampia (Euphorbiaceae): Divergent patterns and ecological consequences. American Journal of Botany, 69(9): 1429-1440, 1982. 
Brasil. 2014. Resolução Consema $n^{\circ} 51$, de 05 de dezembro de 2014. Reconhece a Lista Oficial das Espécies da Flora Ameaçada de Extinção no Estado de Santa Catarina e dá outras providências. Diário Oficial da União. <http://www.sds.sc.gov.br/index. $\mathrm{php} /$ biblioteca/consema/legislacao/resolucoes/325resolucao-consema-no-512014-1/file> Acesso em: 30/01/2018.

Bechara FC, Topanotti LR, Schwade GM, Silva VM \& Estevan VA. Flora fanerogâmica da região sudoeste do estado do Paraná, Brasil: uso e conservação. Acta Biológica Catarinense, 5(2): 25-46, 2018.

Cordeiro I. Dalechampia purpurata Cordeiro (Euphorbiaceae), a new species from Chapada Diamantina, Bahia, Brazil. Kew Bulletin, 53(2): 467-470, 1998.

Dalmolin E, Zanin A \& Trevisan R. Zizaniopsis longhi-wagnerae (Poaceae, Ehrhartoideae), a New Grass from Montane Grasslands of Santa Catarina, Brazil. Systematic Botanic, 40(3): 755-760, 2015.

Dettke GA, Crespão LMP, Siquerolo LV, Siqueira EL \& Caxambú MG. Floristic composition of the Seasonal Semideciduous Forest in Southern Brazil: Reserva Biológica das Perobas. Acta Scientiarum. Biological Sciences, 40: 1-14, 2018.

Flora do Brasil 2020 em construção. Jardim Botânico do Rio de Janeiro. < http: //floradobrasil.jbrj.gov.br/ > Acesso em: 04/03/2020.

Funez LA, Hassemer G \& Trevisan R. Rediscovery, typification, and conservation assessment of Sarathe ustulata (Maranthaceae). Phytotaxa, 255(1): 91-98, 2016.

Funez LA, Hassemer G \& Ferreira JPR. Rediscovery of Senecio reitzianus (Asteraceae), a species believed to be possibly extinct, on Santa Catarina Island, southern Brazil. Phytotaxa, 291(3): 183-191, 2017.

Garcia LM, Romagnolo MB \& Souza LA. Flora Vascular de um Remanescente de Floresta Estacional Semidecidual, no município de Maringá, Paraná, Brasil. Revista em Agronegócio e Meio Ambiente, 10(2): 501-532, 2017.

Hassemer G, Ferreira JPR, Funez LA \& Medeiros JD. Commelina catharinensis (Commelinaceae): a narrow endemic and endangered new species from Santa Catarina, southern Brazil. Phytotaxa, 246(1): 49-60, 2016.

Hassemer G \& Rønsted N. Yet another new species from one of the best-studied neotropical areas: Plantago humboldtiana (Plantaginaceae), an extremely narrow endemic new species from a waterfall in southern Brazil. PeerJ, 4: e2050, 2016.

IUCN (International Union for Conservation of Nature). 2012. IUCN Red List Categories and Criteria. Version 3.1. 2nd ed. IUCN, Gland, 32p.
IUCN (International Union for Conservation of Nature). 2017. Guidelines for Using the IUCN Red List Categories and Criteria. Version 13. IUCN, Gland, 108p.

Linnaeus C. 1754. Species Plantarum. v.2. Estocolmo. 1200p.

Pereira-Silva RA, Athiê-Souza SM, Secco RS, Mello AL $\&$ Sales MF. Dalechampia erythrostyla (Euphorbiaceae), a New species from Northeastern Brazil. Systematic Botany, 41(4): 989-995, 2016.

Rambo B. 1960. Euphorbiaceae Riograndenses. Pesquisas. Botânica, 9: 1-78.

Radcliffe-Smith A. 2001. Genera Euphorbiacearum. Kew Publishing, 231p.

Radford AE, Dickison WC, Massey J \& Bell CR. 1998. Vascular Plant Systematic. Ed. Harper Collins, 70p.

Rossetto EFS \& Vieira AOS. Vascular Flora of the Mata dos Godoy State Park, Londrina, Paraná, Brazil. Check List, 9(5): 1020-1034, 2013.

Sanches MC. 1997. Espécies de lianas da Reserva Municipal de Santa Genebra, Campinas - SP: Longevidade das sementes e crescimento inicial. Dissertação (Mestrado em Ciências Biológicas). Universidade Estadual de Campinas. 96p.

Smith LB \& Downs RJ. 1959. Resumo Preliminar das Euphorbiáceas em Santa Catarina. Sellowia. 15: 155p.

Smith LB \& Downs RJ. 1988. Euphorbiaceás. In: Reitz R. (ed.) Flora Ilustrada Catarinense, Herbário Barbosa Rodrigues, 408p.

Sobral M, Molz M \& Vieira FCS. Two new species and one nomenclatural note in Myrtaceae from Santa Catarina, Brazil. Phytotaxa, 425(2): 96-104, 2019.

Stevens PF. 2001 em continuidade. Angiosperm Phylogeny Website. Version 12, July 2012. < http:// www.mobot.org/mobot/research/apweb/> Acesso em: 22/01/2018.

Thiers B. 2018. Index Herbariorum: A global directory of public herbaria and associated staff. New York Botanical Garden"s Virtual Herbarium. <http://sweetgum.nybg. org/science/ih/> Acesso em: 20/01/2020.

Trochez LFC et al. Apresentação Checklist de las fenorogamas del Parque Nacional del Iguazú, Foz de Iguazú, Brasil. Relea, 1(2): 71-102, 2017.

Vibrans AC, Sevegnani L, Gasper AL \& Lingner DV. Inventário Florístico Florestal de Santa Catarina: Diversidade e Conservação dos Remanescentes Florestais. Blumenau: Ed. Edifurb 1: 344p, 2014.

Vieira FCS. 2020. A new species of Myrceugenia (Myrtaceae) from Southern Brazil. Phytotaxa, 435(2), 2020. 
Webster GL. Three new species of Dalechampia (Euphorbiaceae) from Brazil. Brittonia, 41(1): 1-9, 1989.

Webster GL. A new brazilian species of Dalechampia subsect. Tryphyllae (Euphorbiaceae). Annals of the Missouri Botanical Garden, 78(1): 255-258, 1991.
Webster GL. Synopsis of the genera and suprageneric taxa of Euphorbiaceae. Annals of the Missouri Botanical Garden, 81: 33-1, 1994.

Webster GL \& Armbruster WS. 1991. A synopsis of the neotropical species of Dalechampia (Euphorbiaceae). Botanical Journal of the Linnean Society, 105: 137- 177, 1991.

Biodiversidade Brasileira - BioBrasil.

Fluxo Contínuo

n. 3, 2020

http://www.icmbio.gov.br/revistaeletronica/index.php/BioBR

Biodiversidade Brasileira é uma publicação eletrônica científica do Instituto Chico Mendes de Conservação da Biodiversidade (ICMBio) que tem como objetivo fomentar a discussão e a disseminação de experiências em conservação e manejo, com foco em unidades de conservação e espécies ameaçadas.

ISSN: 2236-2886 